\title{
вмJ Global Health Unseen and unheard: African children with cancer are consistently excluded from clinical trials
}

\author{
Emmanuella Amoako (D) , ${ }^{1,2,3}$ Desmond Tanko Jumbam (D) , ${ }^{4}$ Yaw Bediako (D) ${ }^{3,5}$
}

To cite: Amoako E, Jumbam DT, Bediako Y. Unseen and unheard: African children with cancer are consistently excluded from clinical trials. BMJ Global Health 2021;6:e004750. doi:10.1136/ bmjgh-2020-004750

Received 14 December 2020 Accepted 16 December 2020

Check for updates

(c) Author(s) (or their employer(s)) 2021. Re-use permitted under CC BY-NC. No commercial re-use. See rights and permissions. Published by BMJ.

${ }^{1}$ Department of Paediatrics and Child Health, Cape Coast Teaching Hospital, Cape Coast, Ghana

${ }^{2}$ Department of Paediatrics and Child Health, University of Cape Coast, Cape Coast, Ghana

${ }^{3}$ Yemaachi Biotechnology, Accra, Ghana

${ }^{4}$ Operation Smile Ghana, Accra, Ghana

${ }^{5}$ West African Centre for Cell Biology of Infectious Pathogens, University of Ghana, Accra, Ghana

\section{Correspondence to} Dr Emmanuella Amoako; emmanuela_amoako@yahoo. com
Cancer in Africa has been described as a runaway train as it now kills more Africans than malaria. ${ }^{12}$ There are an estimated 1 million new cases of cancer on the continent every year and this is expected to double by $2030 .{ }^{3}$ Cancer in Africa is characterised by high mortality and the disparity between mortality rates in Africa and high-income countries (HIC) is most striking for childhood cancers with mortality rates as high as $80 \%$ compared with $20 \%$ in HICs like the USA and Canada. ${ }^{4}$ Despite the stark disparity in burden $(85 \%$ of childhood cancers occur in low and middle-income countries ${ }^{5}$ ) and mortality rates of childhood cancers in Africa, access to clinical trials, which are vital for the development of effective and safe therapeutics and treatment, remains unacceptably low for African children.

Over the last two decades, clinical trials have played a key role in improving survival rates for children with cancer in HICs. ${ }^{6}$ For example, in England, patients with cancer enrolled in clinical trials have significantly higher survival rates than similar patients with cancer who are not enrolled in trials. ${ }^{7}$ The National Comprehensive Cancer Network has stated that clinical trials are the best way to manage patients with cancer. ${ }^{28}$ Unfortunately, this is not possible for most African countries where very poor prognosis has been linked to late presentation, malnutrition, treatment abandonment, lack of proper supportive services and need for drug dose modification. Undoubtedly, all these factors significantly affect low survival rates of childhood cancers in Africa and must be addressed systematically by strengthening health systems. ${ }^{59}$ However, the molecular and genetic composition of cancer types, which can influence treatment options, is often neglected in discussions on how to tackle childhood cancers in Africa.

Important ethnic differences exist in the prevalence and outcomes of childhood cancers. In their recent review, Eche and Aronowitz observed that despite Black children having lower risks of acute lymphoblastic lymphoma (ALL), 15 of the
16 studies they reviewed reported inferior survival rates for Black children with ALL compared with their White and Hispanic counterparts. ${ }^{10}$ In agreement with this, epidemiological studies of children with leukaemia conducted in the USA and UK observed that unfavourable prognostic characteristics were more common in ethnic minorities compared with White, non-Hispanic children possibly contributing to disparities in survival of minority children with ALL. 112

Oncology clinical trials are crucial for developing novel and safe tools for the prevention, diagnosis, screening and treatment of cancer. Unfortunately, Africa seems to be largely excluded from cancer research. Although the continentaccounts for $17 \%$ of the world's population, only $2 \%$ of participants of genomics studies are of African descent compared with $78 \%$ of European ancestry. ${ }^{13}$ Even more alarming, only $0.06 \%$ of analysed data from the UK Biobank were from people of African ancestry. ${ }^{14}$

The exclusion of African populations in childhood cancer research is deeply troubling. A review of cancer clinical trials in Africa found that only 20 of 54 African countries surveyed hosted clinical trials with the majority in four countries: Egypt, South Africa, Algeria and Kenya. ${ }^{1}$ Only 109 cancer clinical trials were being conducted in Africa with a population of 1.2 billion people compared with over 6800 in the USA with a population of 328 million. ${ }^{15}$ Regrettably, the exclusion of African participants from the majority of clinical trials means that a large proportion of paediatric patients with cancer are not represented in the very research efforts aimed at combating these diseases.

Children are still excluded from the few cancer clinical trials available in Africa. Currently, most ongoing cancer clinical trials in Africa are funded by academic institutions and pharmaceutical companies based in the USA, Switzerland and Egypt. ${ }^{1}$ The top sponsor is Hoffmann-La Roche, a Swiss pharmaceutical company. However, it is likely that very few of these clinical trials focus 
on childhood cancers as the top cancers studied are breast, cervical, lung and gastrointestinal.

The untoward exclusion of African children in clinical trials occurs mainly due to a perceived lack of research capacity in Africa. Clinical research activity in many African countries remains low mainly due to limited research and development $(\mathrm{R} \& \mathrm{D})$ funding. Despite their political commitment to spend at least $2 \%$ of gross domestic product (GDP) on R\&D, collectively, African countries only spend about $0.5 \%$ of their GDP on R\&D compared with the $2.2 \%$ global average. ${ }^{16}$ Ngoma and Ngoma have argued that where resources are limited, policymakers tend to view cancer research as a luxury rather than a necessity. ${ }^{17}$ As a consequence, there are few dedicated and skilled research teams which coupled with unreliable internet access, poor or no access to scientific literature, inadequate regulatory structure and poor-quality assurance result in an overall lack of capacity to implement cancer research projects and meet international Good Clinical Practice standards. These factors, together with therapeutic misconception among the general public, prevent more home-grown cancer clinical trials on the continent.

Despite the considerable challenges involved, the combination of a fast-growing, largely treatment-naïve population, large burden of disease and the greatest human genetic diversity of any region in the world, Africa is actually uniquely suited for clinical research. Increasing the number of clinical trials conducted in Africa will certainly require African governments to dedicate considerable resources towards scientific capacity building in their respective countries; however, the key to success will be greater collaboration and integration across the continent. More collaboration is needed between African researchers, research sites and regulatory bodies. ${ }^{18}$ Collaboration between national regulatory bodies to reduce the bureaucratic challenges in conducting trials in 54 different African countries with 54 different regulatory jurisdictions will make Africa a lot more attractive to clinical trial sponsors. Similarly, collaboration between African researchers across sites can yield better science and foster mentorship and training opportunities. Collaboration between research sites across the continent and the world can also help standardise treatment protocols/guidelines and improve efficiency allowing for local evidence-based solutions to be generated and more easily shared and implemented.

The conspicuous absence of African children from cancer clinical trials highlights the global disparities that exist in cancer research and care. This disparity must be addressed if the WHO global initiative for childhood cancers is to achieve its goal of at least $60 \%$ survival for all children with cancer by $2030 .{ }^{19}$ This will not be an easy task, but the battle against childhood cancers will be fought in Africa and is not one the world can afford to lose.

Twitter Emmanuella Amoako @drellaamoako, Desmond Tanko Jumbam @desmondtanko and Yaw Bediako @YawBediako_
Contributors All authors contributed equally to this paper.

Funding The authors have not declared a specific grant for this research from any funding agency in the public, commercial or not-for-profit sectors.

Competing interests None declared.

Patient consent for publication Not required.

Provenance and peer review Not commissioned; internally peer reviewed.

Data availability statement There are no data in this work.

Open access This is an open access article distributed in accordance with the Creative Commons Attribution Non Commercial (CC BY-NC 4.0) license, which permits others to distribute, remix, adapt, build upon this work non-commercially, and license their derivative works on different terms, provided the original work is properly cited, appropriate credit is given, any changes made indicated, and the use is non-commercial. See: http://creativecommons.org/licenses/by-nc/4.0/.

\section{ORCID iDs}

Emmanuella Amoako http://orcid.org/0000-0002-2965-7597

Desmond Tanko Jumbam http://orcid.org/0000-0002-3062-2519

Yaw Bediako http://orcid.org/0000-0001-9786-7564

\section{REFERENCES}

1 Odedina FT, Shamley D, Okoye I, et al. Landscape of oncology clinical trials in Africa. JCO Glob Oncol 2020;6:932-41.

2 Graef KM, Okoye I, Ohene Oti NO, et al. Operational strategies for clinical trials in Africa. JCO Glob Oncol 2020;6:973-82.

3 ICEC. Africa's Emerging Cancer Crisis: A Call to Action, 2017. Available: https://www.iceccancer.org/africas-emerging-cancer-crisis-call-action/

4 WHO. Cancer in children. Available: https://www.who.int/newsroom/fact-sheets/detail/cancer-in-children

5 Yaris N, Mandiracioglu A, Büyükpamukcu M. Childhood cancer in developing countries. Pediatr Hematol Oncol 2004;21:237-53.

6 Bond MC, Pritchard S. Understanding clinical trials in childhood cancer. Paediatr Child Health 2006;11:148.

7 Hough R, Sandhu S, Khan M, et al. Are survival and mortality rates associated with recruitment to clinical trials in teenage and young adult patients with acute lymphoblastic leukaemia? A retrospective observational analysis in England. BMJ Open 2017;7:e017052.

8 NCCN. NCCN oncology research program (orp). Available: https://www. nccn.org/clinical_trials/clinicians.aspx

9 Devex. Opinion: childhood cancers in Ghana - we must do more to protect the vulnerable among US, 2020. Available: https://www.devex. $\mathrm{com} /$ news/sponsored/opinion-childhood-cancers-in-ghana-we-mustdo-more-to-protect-the-vulnerable-among-us-97841

10 Eche IJ, Aronowitz T. A literature review of racial disparities in overall survival of black children with acute lymphoblastic leukemia compared with white children with acute lymphoblastic leukemia. J Pediatr Oncol Nurs 2020;37:180-94.

11 Aldrich MC, Zhang L, Wiemels JL, et al. Cytogenetics of Hispanic and white children with acute lymphoblastic leukemia in California. Cancer Epidemiol Biomarkers Prev 2006;15:578-81.

12 Njoku K, Basta N, Mann KD, et al. Socioeconomic variation in survival from childhood leukaemia in northern England, 1968-2010. Br J Cancer 2013;108:2339-45.

13 Sirugo G, Williams SM, Tishkoff SA. The missing diversity in human genetic studies. Cell 2019;177:26-31.

14 Ben-Eghan C, Sun R, Hleap JS, et al. Don't ignore genetic data from minority populations. Nature 2020;585:184-6.

15 National Cancer Institute. Comprehensive cancer information, 1980. Available: https://www.cancer.gov/

16 Atabong AB. Africa's medical scientists are struggling to get funding to back their research. Quartz Africa. Available: https://qz.com/africa/ 1767967/african-medical-scientists-struggle-for-research-funding/

17 Ngoma T, Ngoma M. Cancer control in Africa: is cancer research a luxury or necessity? Ecancermedicalscience 2019;13:947.

18 Solarin O, Mohammed SI, Ndlovu N, et al. Partnerships and collaborations: the right alliances for clinical trials in Africa. JCO Glob Oncol 2020;6:954-8.

19 WHO. Global initiative for childhood cancer. WHO. Available: http:// www.who.int/cancer/childhood-cancer/en/ 